\title{
Packed Red Blood Cells
}

National Cancer Institute

\section{Source}

National Cancer Institute. Packed Red Blood Cells. NCI Thesaurus. Code C126363.

The red blood cells from a unit of whole blood following removal of most of the plasma, leaving a unit with a hematocrit of about $60 \%$. 